ARTICLE

Received 21 May 2014 | Accepted 21 Aug 2014 | Published 22 Sep 2014

DOI: $10.1038 /$ ncomms 6040

OPEN

\title{
Platinum-modified covalent triazine frameworks hybridized with carbon nanoparticles as methanol-tolerant oxygen reduction electrocatalysts
}

Kazuhide Kamiya ${ }^{1}$, Ryo Kamai ${ }^{2,3}$, Kazuhito Hashimoto ${ }^{1}$ \& Shuji Nakanishi ${ }^{1}$

Covalent triazine frameworks, which are crosslinked porous polymers with two-dimensional molecular structures, are promising materials for heterogeneous catalysts. However, the application of the frameworks as electrocatalysts has not been achieved to date because of their poor electrical conductivity. Here we report that platinum-modified covalent triazine frameworks hybridized with conductive carbon nanoparticles are successfully synthesized by introducing carbon nanoparticles during the polymerization process of covalent triazine frameworks. The resulting materials exhibit clear electrocatalytic activity for oxygen reduction reactions in acidic solutions. More interestingly, the platinum-modified covalent triazine frameworks show almost no activity for methanol oxidation, in contrast to commercial carbon-supported platinum. Thus, platinum-modified covalent triazine frameworks hybridized with carbon nanoparticles exhibit selective activity for oxygen reduction reactions even in the presence of high concentrations of methanol, which indicates potential utility as a cathode catalyst in direct methanol fuel cells.

\footnotetext{
${ }^{1}$ Department of Applied Chemistry, The University of Tokyo, 7-3-1 Hongo, Bunkyo-ku, Tokyo 113-8656, Japan. ${ }^{2}$ Research Center for Advanced Science and Technology, The University of Tokyo, 1-5-3 Komaba, Meguro-ku, Tokyo 153-8904, Japan. ${ }^{3}$ Core Technologies Development Center, Eco Solutions Company, Panasonic Corporation, 1048 Kadoma, Kadoma-city, Osaka 571-8686, Japan. Correspondence and requests for materials should be addressed to K.H. (email: hashimoto@light.t.u-tokyo.ac.jp) or to S.N. (email: nakanishi@light.t.u-tokyo.ac.jp).
} 
C ovalent organic frameworks (COFs) have attracted a keen attention as novel catalyst platforms ${ }^{1-6}$ because of their unique physicochemical properties, including their nano-porous structure, mechanical robustness and high design flexibility. For example, Ding et $a l^{7}$ reported that a palladium-modified imine-linked COF catalysed Suzuki-Miyaura coupling reactions with a high stability and an easy recyclability ${ }^{7}$. Chan-Thaw et al. deposited palladium nanoparticles on covalent triazine frameworks (CTFs) and demonstrated that this material was an effective catalyst for liquid-phase glycerol oxidation ${ }^{8}$. Another interesting example of a COF-based catalyst is platinummodified CTF (Pt-CTF) developed by Palkovits et al. ${ }^{9,10}$, which has been known to function as a heterogeneous (solid) catalyst for partial oxidation of methane $\left(\mathrm{CH}_{4}\right)$ to methylbisulfate $\left(\mathrm{CH}_{3} \mathrm{OSO}_{3} \mathrm{H}\right)$ in $\mathrm{H}_{2} \mathrm{SO}_{4}$ using oleum as an oxidant The Pt-CTF was developed by being inspired by Pt-bipyrimidine complex, known as a Periana catalyst, which could catalyse the same partial oxidation reaction ${ }^{11,12}$. Thus, the work carried out by Palkovits et al. is important in that they developed the concept of molecular complex catalysts to the robust heterogeneous Pt-CTF materials.

Pt-CTFs are attractive also as heterogeneous electrocatalysts, since molecular Pt complexes with a single metal centre is known to exhibit reaction selectivity in some homogeneous redox reactions, such as alkane oxidation ${ }^{13,14}$ and carbon dioxide reduction reactions ${ }^{15}$. Considering that molecular complex-based electrocatalysts are generally unstable, it is expected that Pt-CTFs can serve as electrocatalysts with both unique selectivity and high robustness. However, CTF-based materials have not previously been applied as electrocatalysts because of their poor electrical conductivity ${ }^{16}$. In the present work, we demonstrate a solution to this problem by synthesizing a hybrid material consisting of Pt-CTF and conductive carbon nanoparticles (CPs). The hybridized material (Pt-CTF/CP) exhibits electrocatalytic activity for oxygen reduction reaction (ORR) in acidic solution with a high methanol tolerance, which is a very attractive property for direct methanol fuel cells (DMFCs) as the methanolcrossover effect is one of the issues to be addressed ${ }^{17-21}$. To the best of our knowledge, this is the first demonstration of the potential for CTF-based materials to serve as electrocatalysts.

\section{Results}

Morphological characterization of the Pt-CTF/CP. Pt-CTF/CP was synthesized by modifying the standard synthesis protocol of Pt-CTF $9,10,22,23$. Briefly, CTFs were obtained by in situ polymerization of 2,6-dicyanopyridinein-molten $\mathrm{ZnCl}_{2}$ containing CPs (the weight ratio of 2,6-dicyanopyridine to CP was 1:1), after which the CTF/CP was impregnated with a platinum chloride salt to obtain Pt-CTF/CP. Scanning electron microscopic (SEM) inspection reveals that the particles of Pt-CTF/CP $(20-200 \mathrm{~nm}$, Fig. 1a) are much smaller than that of Pt-CTF polymerized without CPs $(1-5 \mu \mathrm{m}$, Fig. $1 \mathrm{~b})$, suggesting that CTF is well mixed with CPs during the in situ polymerization. Then, we conducted high-resolution transmission electron microscopy (Fig. 1c) and the corresponding high-angle annular dark-field scanning transmission electron microscopy (Fig. 1d), the latter of which is a powerful tool for discerning individual heavy atoms ${ }^{24-26}$. It was confirmed that the bright spots corresponding to Pt atoms (the sizes $<0.5 \mathrm{~nm}$ ) were uniformly dispersed and almost no $\mathrm{Pt}$ nanoparticles (the sizes $>1 \mathrm{~nm}$ ) were observed (Fig. 1d). Such bright spots could not be observed on the CPs (without Pt-CTF) as shown in Supplementary Fig. 1. Figure 1e exhibits another high-resolution transmission electron microscopy image and the corresponding elemental maps (carbon, nitrogen and platinum) obtained by energy dispersive X-ray (EDX) technique. Notably, the EDX maps revealed that $\mathrm{Pt}$ and $\mathrm{N}$ atoms are localized at the edges of CPs, strongly suggesting that CPs (or the aggregates) are covered with Pt-CTF as schematically shown in Fig. 1f.

Next, the nitrogen adsorption-desorption isotherms were obtained to analyse the pore structure of Pt-CTF/CP (Supplementary Fig. 2). Type IV isotherm and $\mathrm{H}_{2}$ hysteresis loop were observed, suggesting that porous structures existed in the synthesized $\mathrm{Pt}-\mathrm{CTF} / \mathrm{CP}^{27,28}$. The pore-size distribution calculated based on nonlocal density functional theory was shown in the inset of Supplementary Fig. 2. Although CP (Ketchenblack) is known to exhibit a peak at $3.6-3.7 \mathrm{~nm}$ (refs 29,30), the synthesized Pt-CTF/CP exhibited peaks at 1.4 and $5.3 \mathrm{~nm}$. The total pore volume and the BET surface area were estimated to be $0.79 \mathrm{~cm}^{3} \mathrm{~g}^{-1}$ and $555 \mathrm{~m}^{2} \mathrm{~g}^{-1}$, respectively.

Electrochemical characterizations of Pt-CTF/CP. Figure 2 shows current density $(j)$ versus potential $(U)$ curves for Pt$\mathrm{CTF} / \mathrm{CP}$ obtained in an oxygen-saturated $0.5 \mathrm{M} \mathrm{H}_{2} \mathrm{SO}_{4}$ solution. Although the ORR activity of Pt-CTF (without CP) was very low (blue curve), the ORR current increased significantly upon hybridization of Pt-CTF with CPs (red curve). This enhancement in ORR activity can be explained on the basis that both the electric conductivity and the electrochemically active surface area of the material were increased by the hybridization with CPs (Fig. 1a,b and Supplementary Table 1). In contrast, when the CTFs (without $\mathrm{Pt}$ ) were hybridized with CPs (green curve), the ORR onset potential was much negative than that of $\mathrm{Pt}-\mathrm{CTF} / \mathrm{CP}$, indicating that the $\mathrm{Pt}$ atoms in $\mathrm{Pt}-\mathrm{CTF} / \mathrm{CP}$ are an active centre for ORR. To the best of our knowledge, this is the first demonstration of the application of a CTF-based material as an electrocatalyst.

Next, to investigate the methanol tolerance of Pt-CTF/CP, we intentionally added methanol to a $0.5-\mathrm{M} \mathrm{H}_{2} \mathrm{SO}_{4}$ solution in the presence of oxygen. Cyclic voltammograms obtained in the presence of methanol are shown in Fig. 3. In case of a commercial $20 \mathrm{wt} \% \mathrm{Pt} / \mathrm{C}$, the oxidation peak of methanol can be clearly observed at around $+600 \mathrm{mV}$ versus RHE (Fig. 3b). After the addition of $1 \mathrm{M}$ methanol, the onset potential of the cathodic current shifted $\sim 200 \mathrm{mV}$ in the negative direction, reaching $580 \mathrm{mV}$ versus RHE. In contrast, surprisingly, the overlap of the methanol oxidation current with that of the ORR was almost negligible for Pt-CTF/CP even in the presence of $1 \mathrm{M}$ methanol. To directly compare the methanol oxidation activity of Pt-CTF/ $\mathrm{CP}$ and $20 \mathrm{wt} \% \mathrm{Pt} / \mathrm{C}$, we obtained cyclic voltammograms in $\mathrm{H}_{2} \mathrm{SO}_{4}$ solution containing methanol in the absence of dissolved oxygen (Fig. 4). The peak currents for methanol oxidation with Pt-CTF/CP (Fig. 4a) were $\sim 1 / 40$ compared with those with Pt/C (Fig. 4b). We confirmed that methanol oxidation is inactive even in $0.5 \mathrm{M} \mathrm{HClO}_{4}$ as shown in Supplementary Fig. 3, which excludes the possibility that the methanol tolerance originated from the suppression of methanol oxidation by strongly adsorbed sulfate/bisulfate ${ }^{31,32}$. Thus, the above results clearly showed that $\mathrm{Pt}-\mathrm{CTF} / \mathrm{CP}$ exhibits little activity with regard to methanol oxidation.

X-ray characterizations of Pt-CTF/CP. Characterizations of $\mathrm{Pt}-\mathrm{CTF} / \mathrm{CP}$ were conducted using various $\mathrm{X}$-ray techniques to obtain information on the molecular mechanism of the methanol tolerance. The surface concentration of each element was determined by an X-ray photoelectron spectroscopy (XPS), and the results are summarized in Table 1 . Peaks assignable to $\mathrm{Pt}$ and $\mathrm{N}$ were confirmed, and the $\mathrm{Pt} / \mathrm{N}$ elemental ratio did not show a clear dependence on the amount of CP (the right column of Table 1), implying that the structures of Pt-CTFs are essentially identical even by hybridizing with CPs. In addition, the surface concentration of $\mathrm{C}$, which was calculated with XPS, became 
a

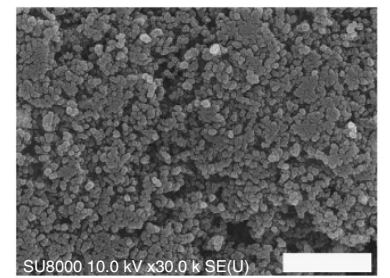

C

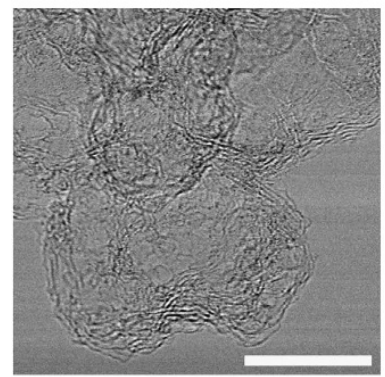

e
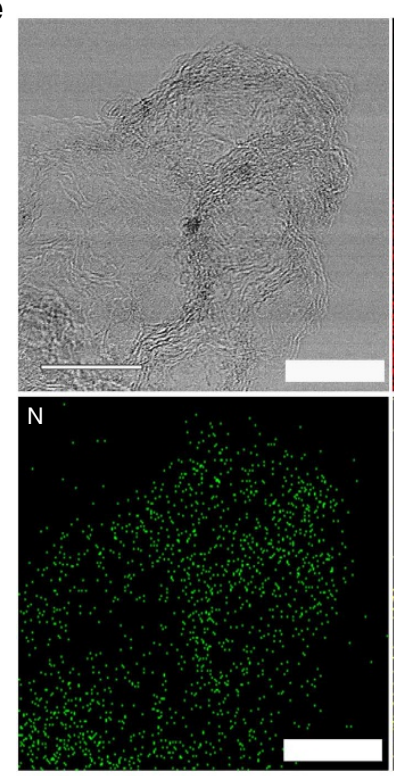

b

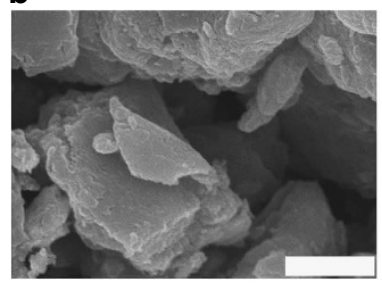

d
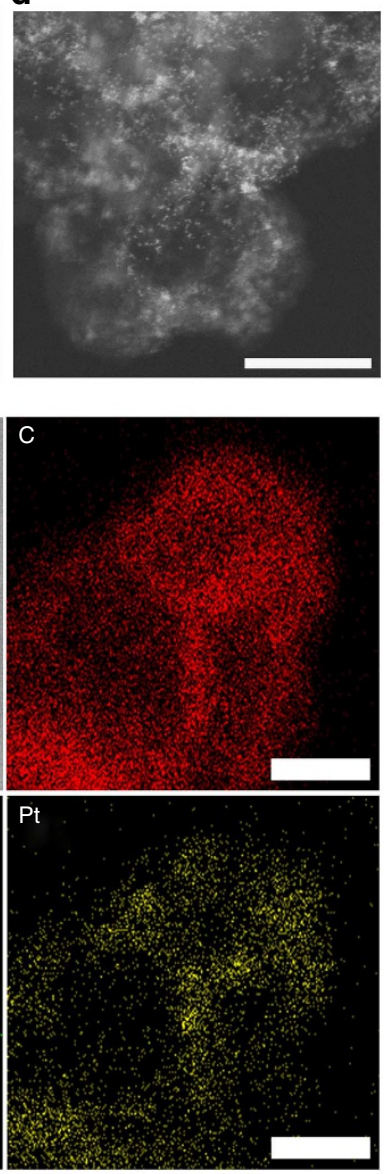

$\mathbf{f}$

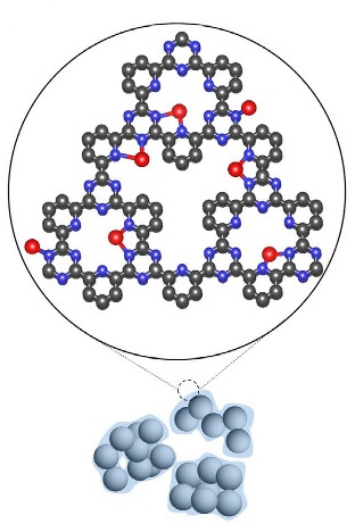

Figure 1 | Electron microscopic images of Pt-CTF/CP. Representative SEM images of (a) Pt-CTF/CP and (b) Pt-CTF. (c) A representative highresolution transmission electron microscopy (HR-TEM) image of Pt-CTF/ $\mathrm{CP}$ and (d) the corresponding high-angle annular dark-field scanning transmission electron microscopy image. (e) Another HR-TEM image of $\mathrm{Pt}-\mathrm{CTF} / \mathrm{CP}$ and the corresponding EDX mappings for $\mathrm{C}, \mathrm{N}$ and $\mathrm{Pt}$ atoms. Scale bar, $1 \mu \mathrm{m}(\mathbf{a}, \mathbf{b})$ and $10 \mathrm{~nm}(\mathbf{c}-\mathbf{e})$. (f) Schematic illustration of Pt-CTF/ $\mathrm{CP}$ (blue: N, red: Pt and black: C, Chlorine atoms are not shown for clarity).

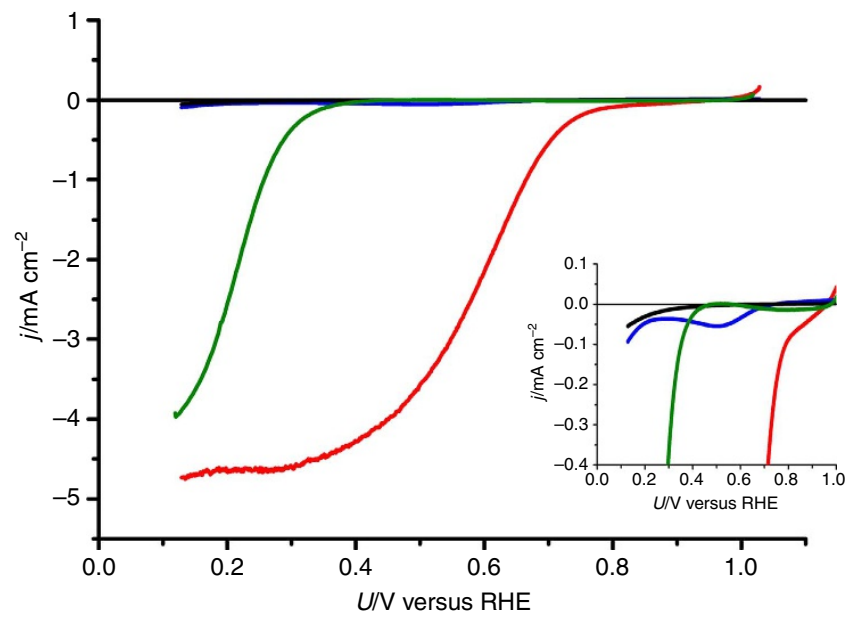

Figure 2 | ORR electrocatalytic activities. $j$ versus $U$ curves for CTF (black), CTF/CP (green), Pt-CTF (blue) and Pt-CTF/CP (red) in $0.5 \mathrm{M}$ $\mathrm{H}_{2} \mathrm{SO}_{4}$ saturated with dissolved oxygen, obtained at a scan rate of $10 \mathrm{mVs}^{-1}$. Rotation rate 1,500 r.p.m. (Inset) Magnified curves.

higher with the increasing ratio of $\mathrm{CP}$. Taking into account that the CP aggregates are uniformly covered by Pt-CTFs (Fig. 1), these results indicated that the thickness of Pt-CTFs is less than the escape depth of photoelectrons (ca. $\sim 3 \mathrm{~nm}$ ) as schematically shown in Fig. 1f, which enabled the Pt-CTF to possess electronic conduction with the CPs.

The details of the electronic structures of Pt-CTFs were investigated by taking XPS and X-ray absorption near-edge structures (XANES; Supplementary Figs 4-7). The Pt- $4 \mathrm{f}_{7 / 2}$ peaks were located at $72.5 \mathrm{eV}$ for Pt-CTF/CP and $72.2 \mathrm{eV}$ for Pt-CTF (Supplementary Fig. 4). These binding energies were over $1 \mathrm{eV}$ higher than those for metal $\mathrm{Pt}(70.9 \mathrm{eV})$, revealing that the valence state of $\mathrm{Pt}$ was $\mathrm{Pt}(\mathrm{II})^{33,34}$. In addition, XANES of $\mathrm{Pt} \mathrm{L}_{3}$ edge shown in Supplementary Fig. 5 exhibited that the white-line intensities at 11,562 eV for Pt-CTF (1.45) and Pt-CTF/CP (1.46) are higher than those for metal $\mathrm{Pt}$ (1.24), indicating that Pt atoms existed as oxidized forms in both Pt-CTF and Pt-CTF/CP ${ }^{35}$. Thus, the Pt-4f XPS and the XANES results also show that there was no formation of Pt aggregates (metal Pt) on Pt-CTFs. Next, we focused on the N-1s XPS spectrum (Supplementary Fig. 6 and Supplementary Table 2). The N-1s peak at $399.2 \mathrm{eV}$ observed for the 2,6-dicyanopyridine (that is, the catalyst monomer, Supplementary Fig. 7) was not observed for the Pt-CTF/CP, indicating that the cyclical trimerization of cyano reaction groups efficiently proceeded. The $\mathrm{N}-1$ s peak of $\mathrm{Pt}-\mathrm{CTF} / \mathrm{CP}$ could be deconvoluted into $\mathrm{C}_{2} \mathrm{NH}(398-399 \mathrm{eV})$ and $\mathrm{C}_{3} \mathrm{~N}(400-401 \mathrm{eV})^{4}$. The peak assigned to $\mathrm{C}_{2} \mathrm{NH}$ was shifted to the higher-energy side upon Pt loading on both CTF and CTF/CP, indicating that the electron density of the $\mathrm{N}$ atoms became lower in the presence of $\mathrm{Pt}$ atoms. The decrease in the electron density of the $\mathrm{N}$ atoms can be explained by considering the formation of Pt-N coordination bonds (this point will be argued later). All the features described above were confirmed even for Pt-CTF (that is, without CPs), indicating that the hybridization with CPs did not influence on the electronic properties of $\mathrm{N}$ atoms in Pt-CTFs.

Next, we conducted extended X-ray absorption fine structure (EXAFS) analyses of $\mathrm{Pt} \mathrm{L}_{3}$ edge to obtain information on the molecular structure of Pt-CTF/CP. Fourier transformations of $k_{3}$-weighted EXAFS oscillations for Pt-CTF/CPs, Pt-CTFs, commercial $\mathrm{Pt}\left(\right.$ bpy) $\mathrm{Cl}_{2}$ (bpy: 2,2'-bipyridine), $\mathrm{PtO}_{2}, \mathrm{~K}_{2} \mathrm{PtCl}_{4}$ and $\mathrm{Pt}$ metal are shown in Fig. 5. The peak corresponding to a $\mathrm{Pt}-\mathrm{Pt}$ bond at $2.6 \AA$ was not observed at all for Pt-CTF/CPs. 

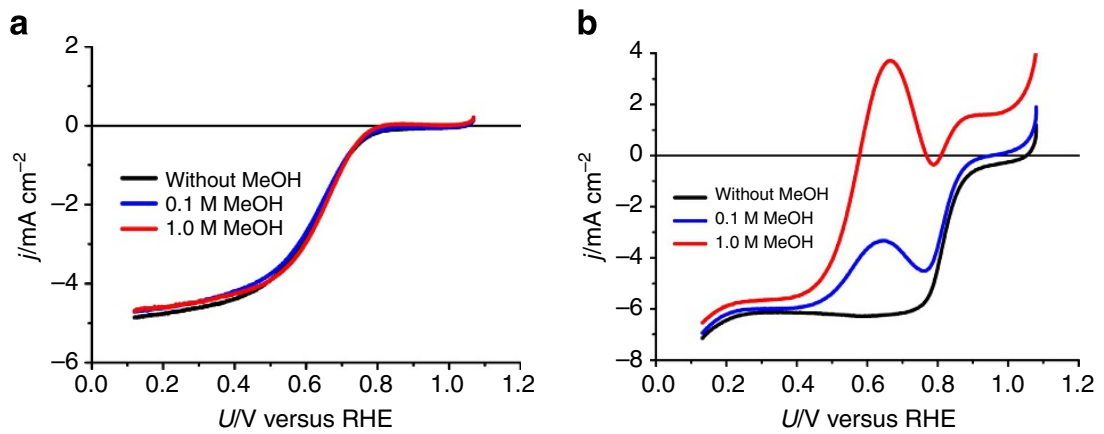

Figure 3 | ORR activities of Pt-CTF/CP and $\mathbf{P t} / \mathbf{C}$ in the presence of methanol. $j$ versus $U$ curves for (a) Pt-CTF/CP and (b) 20 wt\% Pt/C in $0.5 \mathrm{M} \mathrm{H} \mathrm{H}_{2} \mathrm{SO}$ saturated with dissolved oxygen. Methanol concentration: (black) $\mathrm{OM}$, (blue) $0.1 \mathrm{M}$ and (red) $1.0 \mathrm{M}$.
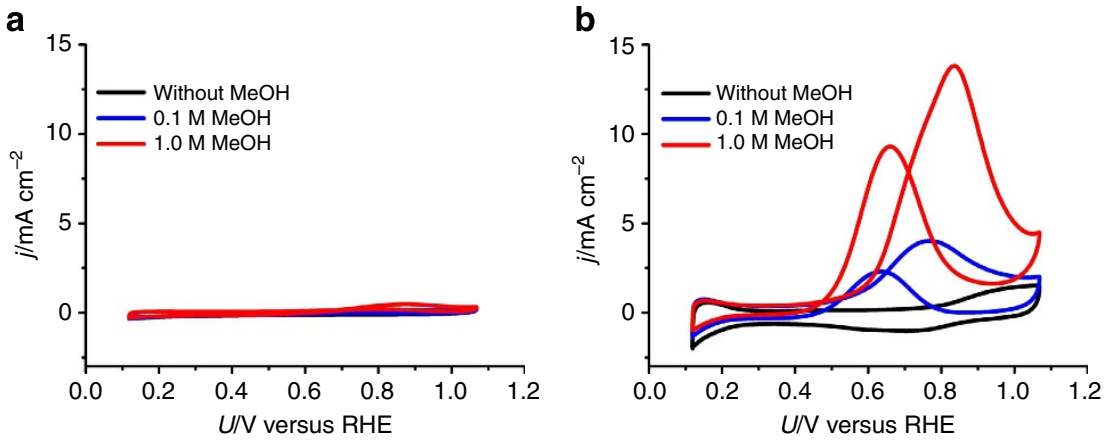

Figure 4 | Methanol oxidation activity of Pt-CTF/CP and Pt/C. $j$ versus $U$ curves for (a) Pt-CTF/CP and (b) 20 wt $\%$ Pt/ $\mathrm{C}$ in $0.5 \mathrm{M} \mathrm{H} \mathrm{H}_{2} \mathrm{SO} 4$ in the absence of oxygen. Methanol concentration: (black) $0 \mathrm{M}$, (blue) $0.1 \mathrm{M}$ and (red) $1.0 \mathrm{M}$.

\begin{tabular}{|c|c|c|c|c|c|}
\hline & C & $\mathbf{N}$ & $\mathbf{P t}$ & $\mathbf{C l}$ & $\mathrm{Pt} / \mathrm{N}$ \\
\hline CTF & 81 & 17 & - & 2.6 & - \\
\hline Pt-CTF & 76 & 15 & 3.0 & 5.5 & 0.20 \\
\hline Pt-CTF/CP & 91 & 5.6 & 1.0 & 2.3 & 0.18 \\
\hline $\begin{array}{l}\mathrm{CP} \text {, carbon nan } \\
\mathrm{X} \text {-ray photoelec } \\
\text { The compositio } \\
\text { results. }\end{array}$ & $\begin{array}{l}\text { F, cov } \\
\text { oscop } \\
\text { omic }\end{array}$ & $\begin{array}{l}\text { azine } \\
\text { TF, Pt }\end{array}$ & $\begin{array}{l}\text { rk; Pt- } \\
\text { d Pt-C }\end{array}$ & inum- & $\begin{array}{l}\text { CTF; XP } \\
\text { the XPS }\end{array}$ \\
\hline
\end{tabular}

Instead, two peaks at $R=1.5$ and $1.9 \AA$ assignable to $\mathrm{Pt}-\mathrm{N}$ and $\mathrm{Pt}-\mathrm{Cl}$ bonds, respectively, were clearly observed, indicating that Pt exists in the form of a single atom as illustrated in Fig. lf. The ratio of the Pt-N peak to the Pt-Cl peak for Pt-CTFs corresponded to that for $\mathrm{Pt}(\mathrm{bpy}) \mathrm{Cl}_{2}$ (model $\mathrm{PtN}_{2} \mathrm{Cl}_{2}$ complex), implying that $\mathrm{Pt}$ atoms mainly existed as $\mathrm{PtN}_{2} \mathrm{Cl}_{2}$. It should be noted here that there was no clear difference in the EXAFS spectra between Pt-CTF/CP and Pt-CTF, indicating that the molecular structure of Pt-CTF is maintained upon the hybridization with CPs.

\section{Discussion}

Let us consider here about the molecular mechanism of the methanol-tolerant ORR electrocatalytic activity of Pt-CTF/CP. First, we consider about the ORR on a single Pt site. An oxygen molecule is known to adsorb on a single Pt atom through either the Griffiths model (side-on adsorption) or the Pauling model (end-on adsorption) $^{36}$. After the adsorption, $\pi$ donation from the oxygen $2 \pi$ orbitals to the unoccupied Pt $5 d$ orbitals, and the $\pi$

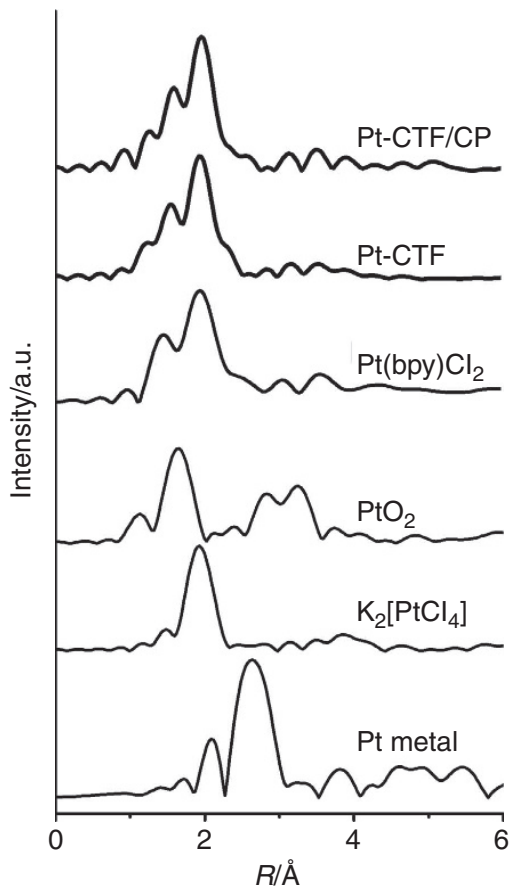

Figure 5 | EXAFS analyses. $k^{3}$-weighted Fourier transform spectra of EXAFS of $\mathrm{Pt} \mathrm{L}_{3}$ edge for Pt-CTF/CP and Pt-CTF. The spectra of $\mathrm{Pt}(\mathrm{bpy}) \mathrm{Cl}_{2}$, $\mathrm{PtO}_{2}, \mathrm{~K}_{2}\left[\mathrm{PtCl}_{4}\right]$ and $\mathrm{Pt}$ metal are also shown as reference.

back donation from occupied Pt $5 d$ orbitals to the oxygen $2 \pi^{\star}$ orbitals could simultaneously occur, resulting in the $\mathrm{O}-\mathrm{O}$ bond activation $^{36,37}$. In fact, Nakamura et al. ${ }^{38}$ revealed using ${ }^{18} \mathrm{O}$ 
isotopic infrared study that a single Pt atom and an oxygen molecule exchanged electrons, forming $\mathrm{Pt}-\mathrm{O}_{2}$ adduct through the side-on adsorption. Li et al..$^{39}$ also demonstrated by using firstprinciples calculations that the $\mathrm{O}-\mathrm{O}$ bond was activated on single Pt site via the $\pi$ back donation through the end-on adsorption, resulting in the weakening of the $\mathrm{O}-\mathrm{O}$ bond. These reported lines of work suggested that electrocatalytic ORR could proceed even on a single Pt atom.

On the contrary, a number of researchers have suggested that at least two $\mathrm{Pt}$ atoms are needed to oxidize methanol ${ }^{40-46}$. It is well known that methanol can be oxidized via a dual-path mechanism on $\mathrm{Pt}$, that is, the carbon monoxide (CO) pathway and the non-CO pathway ${ }^{44,45,47}$. Cuesta ${ }^{45,48}$ revealed by using cyanide-modified Pt electrode that dehydrogenation reaction of methanol to $\mathrm{CO}$, a critical step of the $\mathrm{CO}$ pathway, required at least three contiguous $\mathrm{Pt}$ sites. As for the non-CO pathway, Osawa and colleagues ${ }^{44}$ proposed a molecular mechanism based on the results obtained from in situ infrared (IR) absorption spectroscopy. They suggested that adsorbed oxygenated species (that is, $\mathrm{O}_{\mathrm{ad}}$ or $\mathrm{OH}_{\mathrm{ad}}$ ) on the Pt site next to the methanol absorption site are needed for first dehydrogenation of the $\mathrm{O}-\mathrm{H}$ bond in methanol. This molecular mechanism was further supported by Kuzume et al. ${ }^{49}$ again by in situ IR absorption spectroscopy. The previous lines of work have thus revealed that at least two adjacent $\mathrm{Pt}$ sites are required for methanol oxidation regardless of whether the reaction proceeds via the $\mathrm{CO}$ or the non-CO pathways. Actually, to the best of our knowledge, there have been no reports of methanol oxidation on a single Pt-atom site. Considering these literatures, the methanol tolerance of Pt/CTF is reasonably explained because the EXAFS results demonstrated that the Pt atoms in Pt/CTF were isolated.

In conclusion, we successfully synthesized Pt-CTF hybridized with $\mathrm{CP}$, preserving its electronic and molecular structure, which exhibited ORR activity in acidic solutions with a high methanol tolerance. The methanol tolerance of the Pt-CTF/CP indicates that the methanol-crossover effect can be ignored. This property allows a considerable increase in the concentration of methanol in DMFC; consequently, the energy density of DMFC is expected to increase because of the use of Pt-CTF/CP. Another interesting aspect of this work is that it is the first demonstration of electrocatalytic function in CTF-based materials. This was achieved by hybridizing non-conductive CTFs with conductive CPs. We anticipate that this methodology could be applied generally to other CTFs with unique catalytic properties.

\section{Methods}

Synthesis procedure of Pt-CTF/CP. CTF/CP was synthesized by polymerization of 2,6-dicyanopyridine in a molten salt of zinc chloride $\left(\mathrm{ZnCl}_{2}\right)$. Specifically, $1.363 \mathrm{~g} \mathrm{ZnCl}_{2}$ (Wako), $0.129 \mathrm{~g}$ 2,6-dicyanopyridine (Sigma) and $0.129 \mathrm{~g}$ KetchenBlack EC600JD were mixed in a globe box. The mixture was placed in a Pyrex glass tube and the tube was sealed, evacuated, heated and kept at a terminal temperature of $400^{\circ} \mathrm{C}$ for $21 \mathrm{~h}$. The resulting powder was washed with $0.1 \mathrm{M} \mathrm{HCl}$, water, tetrahydrofolate and acetonitrile, and dried in vacuo. Pt atoms were modified by impregnation in $160 \mathrm{mM} \mathrm{K} \mathrm{K}_{2}\left[\mathrm{PtCl}_{4}\right]$ (Wako) aqueous solution at $60{ }^{\circ} \mathrm{C}$ for $4 \mathrm{~h}$ before being washed with water and acetone.

\footnotetext{
Electrochemical characterization. Electrochemical activity for ORR was evaluated using a rotating disk electrode. Working electrodes were first prepared by dispersing $5 \mathrm{mg}$ of powder samples in $175 \mu \mathrm{l}$ ethanol and $47.5 \mu \mathrm{l}$ Nafion solution ( $5 \mathrm{wt} \%$ solution in a mixture of lower aliphatic alcohols and water, Aldrich). A 7- $\mu \mathrm{l}$ aliquot of ink was dropped on a glassy carbon electrode $\left(0.196 \mathrm{~cm}^{-2}\right)$. The catalyst loading was controlled at $0.8 \mathrm{mg} \mathrm{cm}^{-2}$. A Pt wire and $\mathrm{Ag} / \mathrm{AgCl}$ (saturated $\mathrm{KCl}$ ) were used as the counter and reference electrodes, respectively. Commercial 20 wt\% Pt/C and Pt-Vulcan XC-72 were purchased from Tanaka Kikinzoku and Fuel Cell Earth, respectively. The electrical conductivity of the catalysts was measured with a resistivity meter (Mitsubishi Chemical, Loresta GP). The working electrode was rotated with a rotation speed of 1,500 r.p.m.
}

Physical characterizations. X-ray photoelectron spectra (Axis Ultra, Kratos Analytical Co.) were taken with monochromated $\mathrm{Al} \mathrm{K} \alpha \mathrm{X}$-rays at $h v=1,486.6 \mathrm{eV}$ For detailed chemical analysis, backgrounds of core-level spectra were subtracted using the Shirley method. N-1s spectra were fitted with Voigt (70\% Gaussian and $30 \%$ Lorentzian) functions. Hard X-ray absorption measurements (XAFS) were performed at the hard X-ray beam line BL01B01 at SPring-8, Japan and by using R-XAS Looper (Rigaku). Transmission-yield spectra were acquired using a double-crystal Si (111) monochromator. The morphological structures were characterized using TEM with an EDX detector (ARM-200F, JEOL) and SEM (SU-8000, Hitachi). The nitrogen adsorption-desorption isotherm at $77 \mathrm{~K}$ was obtained by a BET (NOVA-4200e, Quantachrome).

\section{References}

1. Cote, A. P. et al. Porous, crystalline, covalent organic frameworks. Science 310, 1166-1170 (2005).

2. Chan-Thaw, C. E., Villa, A., Prati, L. \& Thomas, A. Triazine-based polymers as nanostructured supports for the liquid-phase oxidation of alcohols. Chem. Eur. J. 17, 1052-1057 (2011).

3. Ding, S.-Y. \& Wang, W. Covalent organic frameworks (COFs): from design to applications. Chem. Soc. Rev. 42, 548-568 (2013).

4. Chan-Thaw, C. E. et al. Influence of periodic nitrogen functionality on the selective oxidation of alcohols. Chem. Asian J. 7, 387-393 (2012).

5. Feng, X., Ding, X. \& Jiang, D. Covalent organic frameworks. Chem. Soc. Rev. 41, 6010-6022 (2012).

6. Pachfule, P., Kandambeth, S., Diaz, D. D. \& Banerjee, R. Highly stable covalent organic framework-Au nanoparticles hybrids for enhanced activity for nitrophenol reduction. Chem. Commun. 50, 3169-3172 (2014).

7. Ding, S.-Y. et al. Construction of covalent organic framework for catalysis: Pd/COF-LZU1 in Suzuki-Miyaura coupling reaction. J. Am. Chem. Soc. 133, 19816-19822 (2011)

8. Chan-Thaw, C. E. et al. Covalent triazine framework as catalytic support for liquid phase reaction. Nano Lett. 10, 537-541 (2010).

9. Palkovits, R., Antonietti, M., Kuhn, P., Thomas, A. \& Schueth, F. Solid catalysts for the selective low-temperature oxidation of methane to methanol. Angew. Chem. Int. Ed. 48, 6909-6912 (2009).

10. Palkovits, R. et al. Development of molecular and solid catalysts for the direct lowtemperature oxidation of methane to methanol. ChemSusChem 3, 277-282 (2010).

11. Periana, R. A. et al. Platinum catalysts for the high-yield oxidation of methane to a methanol derivative. Science 280, 560-564 (1998).

12. Kua, J., Xu, X., Periana, R. A. \& Goddard, W. A. Stability and thermodynamics of the $\mathrm{PtCl}_{2}$ type catalyst for activating methane to methanol: a computational study. Organometallics 21, 511-525 (2002).

13. Shilov, A. E. \& Shul'pin, G. B. Activation of C-H bonds by metal complexes. Chem. Rev. 97, 2879-2932 (1997).

14. Stahl, S. S., Labinger, J. A. \& Bercaw, J. E. Homogeneous oxidation of alkanes by electrophilic late transition metals. Angew. Chem. Int. Ed. 37, 2181-2192 (1998)

15. Mitton, S. J. \& Turculet, L. Mild reduction of carbon dioxide to methane with tertiary silanes catalyzed by platinum and palladium silyl pincer complexes. Chem. Eur. J. 18, 15258-15262 (2012).

16. Guo, J. et al. Conjugated organic framework with three-dimensionally ordered stable structure and delocalized $\pi$ clouds. Nat. Commun. 4, 2736 (2013).

17. Krewer, U., Vidakovic-Koch, T. \& Rihko-Struckmann, L. Electrochemical oxidation of carbon-containing fuels and their dynamics in low-temperature fuel cells. Chemphyschem 12, 2518-2544 (2011).

18. Argyropoulos, P., Scott, K. \& Taama, W. M. The effect of operating conditions on the dynamic response of the direct methanol fuel cell. Electrochim. Acta 45, 1983-1998 (2000).

19. Daems, N., Sheng, X., Vankelecom, I. F. J. \& Pescarmona, P. P. Metal-free doped carbon materials as electrocatalysts for the oxygen reduction reaction. J. Mater. Chem. A 2, 4085-4110 (2014)

20. Gewirth, A. A. \& Thorum, M. S. Electroreduction of dioxygen for fuel-cell applications: materials and challenges. Inorg. Chem. 49, 3557-3566 (2010).

21. Brownson, D. A. C., Kampouris, D. K. \& Banks, C. E. An overview of graphene in energy production and storage applications. J. Power Sources 196, 4873-4885 (2011).

22. Kuhn, P., Thomas, A. \& Antonietti, M. Toward tailorable porous organic polymer networks: a high-temperature dynamic polymerization scheme based on aromatic nitriles. Macromolecules 42, 319-326 (2009).

23. Kuhn, P., Antonietti, M. \& Thomas, A. Porous, covalent triazine-based frameworks prepared by ionothermal synthesis. Angew. Chem. Int. Ed. 47, 3450-3453 (2008).

24. Herzing, A. A., Kiely, C. J., Carley, A. F., Landon, P. \& Hutchings, G. J. Identification of active gold nanoclusters on iron oxide supports for CO oxidation. Science 321, 1331-1335 (2008).

25. Sun, S. et al. Single-atom catalysis using Pt/graphene achieved through atomic layer deposition. Sci. Rep. 3, 1775 (2013).

26. Qiao, B. et al. Single-atom catalysis of $\mathrm{CO}$ oxidation using $\mathrm{Pt}_{1} / \mathrm{FeO}_{\mathrm{x}}$. Nat. Chem. 3, 634-641 (2011) 
27. Kuhn, P., Forget, A., Su, D., Thomas, A. \& Antonietti, M. From microporous regular frameworks to mesoporous naterials with ultrahigh surface area: dynamic reorganization of porous polymer networks. J. Am. Chem. Soc. 130, 13333-13337 (2008).

28. Kuhn, P., Forget, A., Hartmann, J., Thomas, A. \& Antonietti, M. Template-free tuning of nanopores in carbonaceous polymers through ionothermal synthesis. Adv. Mater. 21, 897-901 (2009).

29. Wang, G. et al. Improving the DMFC performance with Ketien Black EC 300J as the additive in the cathode catalyst layer. J. Power Sources 180, 176-180 (2008).

30. Tashima, D., Yoshitama, H., Otsubo, M., Maeno, S. \& Nagasawa, Y. Evaluation of electric double layer capacitor using Ketjenblack as conductive nanofiller. Electrochim. Acta 56, 8941-8946 (2011).

31. Cohen, J. L., Volpe, D. J. \& Abruna, H. D. Electrochemical determination of activation energies for methanol oxidation on polycrystalline platinum in acidic and alkaline electrolytes. Phys. Chem. Chem. Phys. 9, 49-77 (2007).

32. Kolics, A. \& Wieckowski, A. Adsorption of bisulfate and sulfate anions on a Pt(111) electrode. J. Phys. Chem. B 105, 2588-2595 (2001).

33. Hidai, S. et al. Platinum oxidation responsible for degradation of platinumcobalt alloy cathode catalysts for polymer electrolyte fuel cells. J. Power Sources 215, 233-239 (2012).

34. Wang, H. et al. Influence of size-induced oxidation state of platinum nanoparticles on selectivity and activity in catalytic methanol oxidation in the gas phase. Nano Lett. 13, 2976-2979 (2013).

35. Russell, A. E. \& Rose, A. X-ray absorption spectroscopy of low temperature fuel cell catalysts. Chem. Rev. 104, 4613-4635 (2004).

36. Toda, T., Igarashi, H., Uchida, H. \& Watanabe, M. Enhancement of the electroreduction of oxygen on Pt alloys with Fe, Ni, and Co. J. Electrochem. Soc. 146, 3750-3756 (1999).

37. Lim, D.-H. \& Wilcox, J. DFT-based study on oxygen adsorption on defective graphene-supported Pt nanoparticles. J. Phys. Chem. C 115, 22742-22747 (2011)

38. Nakamura, A., Tatsuno, Y., Yamamoto, M. \& Otsuka, S. Oxygen-18 isotopic infrared study of dioxygen-transition metal complexes. J. Am. Chem. Soc. 93 6052-6058 (1971).

39. Li, T. \& Balbuena, P. B. Computational studies of the interactions of oxygen with platinum clusters. J. Phys. Chem. B 105, 9943-9952 (2001).

40. Gasteiger, H. A., Markovic, N., Ross, P. N. \& Cairns, E. J. Electro-oxidation of small organic molecules on well-characterized Pt-Ru alloys. Electrochim. Acta 39, 1825-1832 (1994).

41. Hernandez-Fernandez, P. et al. Relevance of the nature of bimetallic PtAu nanoparticles as electrocatalysts for the oxygen reduction reaction in the presence of methanol. J. Power Sources 177, 9-16 (2008).

42. Kim, Y. T. et al. Fine size control of platinum on carbon nanotubes: From single atoms to clusters. Angew. Chem. Int. Ed. 45, 407-411 (2006).

43. Nishanth, K. G., Sridhar, P., Pitchumani, S. \& Shukla, A. K. A DMFC with methanol-tolerant-carbon-supported-Pt-Pd-alloy cathode. J. Electrochem. Soc. 158, B871-B876 (2011).
44. Chen, Y. X., Miki, A., Ye, S., Sakai, H. \& Osawa, M. Formate, an active intermediate for direct oxidation of methanol on Pt electrode. J. Am. Chem. Soc. 125, 3680-3681 (2003).

45. Cuesta, A. At least three contiguous atoms are necessary for $\mathrm{CO}$ formation during methanol electrooxidation on platinum. J. Am. Chem. Soc. 128, 13332-13333 (2006).

46. McNicol, B. D. Electrocatalytic problems associated with the development of direct methanol-air fuel cells. J. Electroanal. Chem. 118, 71-87 (1981).

47. Lai, S. C. S., Lebedeva, N. P., Housmans, T. H. M. \& Koper, M. T. M. Mechanisms of carbon monoxide and methanol oxidation at single-crystal electrodes. Top Catal. 46, 320-333 (2007).

48. Cuesta, A. Atomic ensemble effects in electrocatalysis: the site-knockout strategy. Chemphyschem 12, 2375-2385 (2011).

49. Kuzume, A., Mochiduki, Y., Tsuchida, T. \& Ito, M. Methanol oxidation on a Pt(111)-OH/O surface. Phys. Chem. Chem. Phys. 10, 2175-2179 (2008)

\section{Acknowledgements}

Synchrotron radiation experiments were performed at the BL01B1 beam line of SPring- 8 with the approval of the Japan Synchrotron Radiation Research Institute (JASRI; Proposal nos 2013B1123 and 2013A1598). We thank Dr T. Ina for his technical support during XAFS measurements at SPring-8.

\section{Author contributions}

K.K., R.K. and S.N. designed the experiments and performed the analyses. K.K., K.H. and S.N. wrote the manuscript.

\section{Additional information}

Supplementary Information accompanies this paper at http://www.nature.com/ naturecommunications

Competing financial interests: The authors declare no competing financial interests

Reprints and permission information is available online at http://npg.nature.com/ reprintsandpermissions/

How to cite this article: Kamiya, K. et al. Platinum-modified covalent triazine frameworks hybridized with carbon nanoparticles as methanol-tolerant oxygen reduction electrocatalysts. Nat. Commun. 5:5040 doi: 10.1038/ncomms6040 (2014).

(c) (i) This work is licensed under a Creative Commons Attribution 4.0 International License. The images or other third party material in this article are included in the article's Creative Commons license, unless indicated otherwise in the credit line; if the material is not included under the Creative Commons license, users will need to obtain permission from the license holder to reproduce the material. To view a copy of this license, visit http://creativecommons.org/licenses/by/4.0/ 